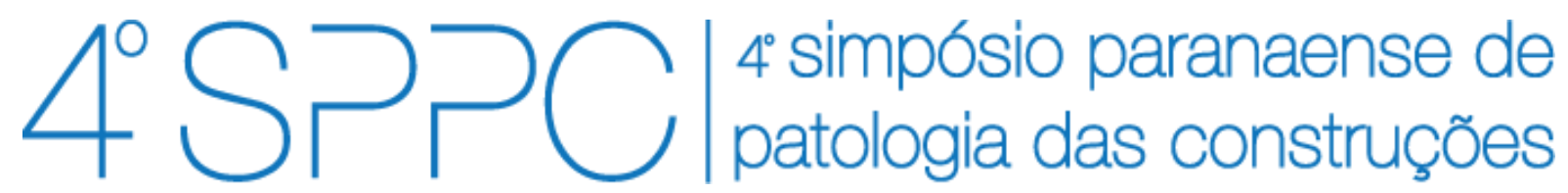

ISSN 2526-7248 artigo n. 4SPPC144, pp. 391-400, 2019

\title{
Avaliação mecânica de concretos com adição de fibras de açaí e curauá
}

Tanobe, Érico Shooji Oliveira de Andrade 1; Miranda, Dayane de Cristo 2; Bronholo, Jeferson Luiz ${ }^{3}$; Marcondes, Carlos Gustavo Nastari 4; Portella, Kleber Franke 5;

Carrera, Gilberto ${ }^{6}$; Bragança, Mariana d'Orey Gaivão Portella ${ }^{7}$

${ }^{1}$ Bolsista de iniciação técnológica, PUCPR/Lactec, erico.tanobe@lactec.org.br

2 Mestranda, Lactec/UFPR, dayane.miranda@lactec.org.br

${ }^{3}$ Especialista, Lactec-IEP/Lactec, jeferson.luiz@lactec.org.br

${ }^{4}$ Doutorando, PUCPR/UFPR, g.marcondes@pucpr.br

${ }^{5}$ Pesquisador doutor, Lactec/UFPR, portella@lactec.org.br

${ }^{6}$ Engenheiro, Grupo Equatorial, gilberto.carrera@equatorialenergia.com.br

${ }^{7}$ Pesquisadora doutora, Lactec/UFPR, mariana.portella@lactec.org.br

Resumo: A inserção de fibras orgânicas em concretos pode se estabelecer como solução adequada, haja vista a possibilidade de recursos alternativos e a redução de impactos ambientais. Nesse contexto, este estudo teve como objetivo avaliar as características físicas e mecânicas de concretos contendo adições de fibras de açaí e curauá, em teores de $0,8 \%$ do volume do concreto. Para tanto, buscou-se investigar por ensaios de resistência à compressão ( 7 e 28 dias), resistência à tração por compressão diametral e resistência ao impacto de corpo duro (28 dias) os efeitos das aplicações das fibras in natura. Pelos resultados obtidos, verificou-se que ambas as fibras conferiram um aumento de $33,3 \%$ na tenacidade dos concretos e que a fibra de açaí contribuíu com um aumento das propriedades mecânicas avalidas no compósito. Logo, as fibras indicaram potencial de aplicação, uma vez que seu uso pode beneficiar a vida útil de estruturas e tornar a destinação de resíduos mais sustentável.

Palavras-chave: concretos, fibras de açaí, fibras de curauá, resistência mecânica.

Abstract: The insertion of organic fibers into concrete can be an adequate solution, given the possibility of alternative resources and the reduction of environmental impacts. In this context, this study aimed to evaluate the physical and mechanical characteristics of concrete containing additions of açaí and curauá fibers, in $0,8 \%$ of the concrete volume. Therefore, it was investigated by tests of resistance to compression ( 7 and 28 days), tensile strenght by diametrical compression and hard body impact resistance (28 days) the effects of the application of the fibers in natura. The results showed that both fibers gave a 33,3\% increase in the toughness of concrete and that the acai fiber contributed with an increase in the mechanical properties evalueted in the composite. Soon, the fibers indicated potential of use, since their use can benift the useful life of structures and make the disposal of waste more sustainable.

Keywords: concretes, açaí fibers, curauá fibers, mechanical resistance. 
TANOBE, É. S. O. A.; MIRANDA, D. C.; BRONHOLO, J. L.; MARCONDES, C. G. N.; PORTELLA, K. F.; CARRERA, G.; BRAGANÇA, M. D. G. P. AVALIAÇÃO MECÂNICA DE CONCRETOS COM ADIÇÃO DE FIBRAS DE AÇAÍ E CURAUÁ. $4^{\circ}$ Simpósio Paranaense de Patologia das Construções (40 SPPC), artigo 4SPPC144, pp. 391 - 400, 2019. DOI: 10.4322/2526-7248.061

\section{Introdução}

A escolha de um material de engenharia para uma aplicação específica, deve levar em conta a sua capacidade de resistir a uma determinada solicitação. Desta forma, torna-se importante avaliar a contribuição de uma tecnologia empregada no desenvolvimento de novos produtos, de maneira que materiais já existentes sejam aprimorados planejadamente reduzindo o impacto ambiental gerado pela extração de suas matérias primas e pelo seu descarte.

O concreto que contém cimento hidráulico, água, agregados e fibras discretas descontínuas é denominado concreto reforçado com fibras (fiber-reinforced concrete, FRC) [1]. Nas últimas décadas, a utilização de fibras vegetais na produção de novos produtos vem sendo uma das formas amplamente exploradas, visto o interesse em fontes de energias renováveis e a reutilização de materiais rejeitáveis como matériaprima e que, consequentemente, permite uma destinação adequada no que se refere aos aspectos ambientais [2; 3].

De modo geral, segundo Siqueira (2006); Freire e Beraldo (2010), o propósito da utilização de fibras em compósitos é a melhoria das propriedades de uma matriz cimentícia inerentemente frágil e propensa à fissuração. Logo as características macroscópicas de maior interesse, no estudo das fibras lignocelulósicas, são aquelas inter-relacionadas com o comportamento no estado pós-fissurado e a absorção de grandes energias, diante de esforços dinâmicos [4;5]. Desta forma, destacou-se para este estudo, as fibras de açaí e de curauá, haja visto o interesse na utilização destes materiais para aplicação local nas regiões do norte do Brasil.

Júnior (2007) destaca que as fibras dispersas na matriz cimentícia reforçam a região adjacente à fissura, melhorando o desempenho do material à flexão. Na Figura 1 está ilustrada uma fissura em um fibrocimento, onde: (1) representa uma fibra rompida, (2) uma fibra arrancada e (3) uma fibra íntegra atravessando a fissura, o que indica que a mesma absorveu parcialmente a energia a qual o material foi submetido [6].

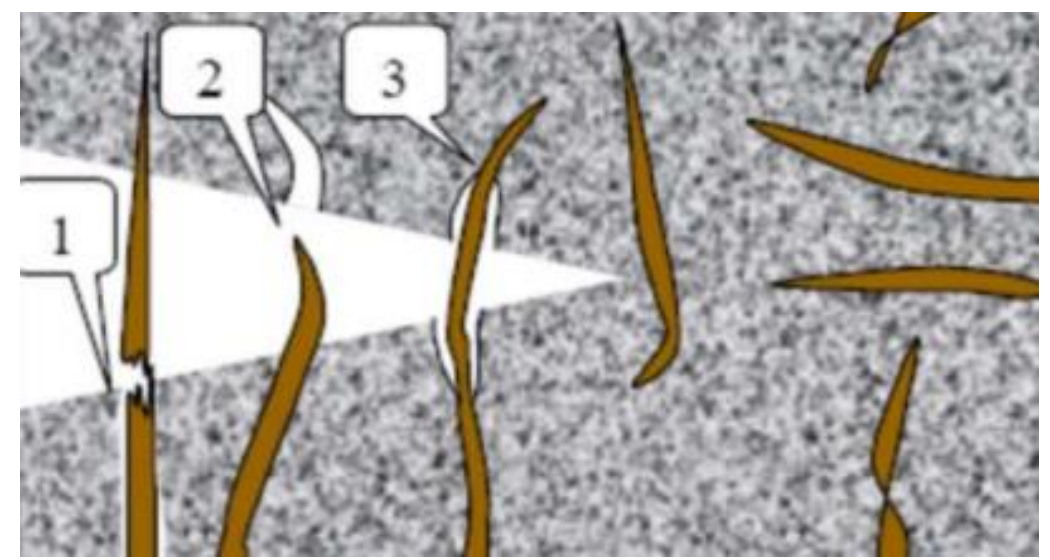

Figura 1: Representação esquemática de uma fissura através do fibrocimento reforçado com fibras vegetais [6].

O açaízero (Euterpe oleraceae Mart.) é uma espécie tropical, tipicamente da Amazônia, que ocupa florestas baixas e montanhas úmidas, abrangendo as regiões do norte do Brasil, principalmente o estado do Pará, estendendo-se até as Guianas e 
TANOBE, É. S. O. A.; MIRANDA, D. C.; BRONHOLO, J. L.; MARCONDES, C. G. N.; PORTELLA, K. F.; CARRERA, G.; BRAGANÇA, M. D. G. P. AVALIAÇÃO MECÂNICA DE CONCRETOS COM ADIÇÃO DE FIBRAS DE AÇAÍ E CURAUÁ. $4^{\circ}$ Simpósio Paranaense de Patologia das Construções (40 SPPC), artigo 4SPPC144, pp. 391 - 400, 2019. DOI: 10.4322/2526-7248.061

a Venezuela [6; 7]. Seu uso é extenso, porém muito utilizado para alimentação e confecção de artesanato local. As fibras de açaí, normalmente são descartadas juntamente das sementes após a extração da polpa, podendo ser removida facilmente, possuindo um comprimento médio na ordem de $12 \mathrm{~mm}$.

Já o curauá (Ananas erectifolius) é uma planta de origem das bromélias, a mesma família do abacaxi, distribuída também pela região do norte do Brasil, principalmente nas regiões conhecidas como baixo Amazonas e oeste do estado do Pará [8; 9]. Dentre suas aplicações, suas fibras são utilizadas para manufaturas de cordas, cestas, tapetes e como reforço de materiais compósitos em geral.

Diante desse contexto, este estudo teve como objetivo a avaliação dos efeitos das adições de fibras de açaí e curauá, em teores de $0,8 \%$ do volume do concreto, separadamente, sob o desempenho físico-mecânico do compósito formado.

\section{Procedimento Experimental}

\subsection{Agregados}

Os agregados miúdo e graúdo foram obtidos da região metropolitana de Curitiba/PR, caracterizados de acordo com os aspectos físico-químicos por Oliveira (2019) [8] e com as normatizações listadas na Tabela 1:

Tabela 1: Normatização utilizada para caracterização dos agregados (Fonte:

Oliveira, 2019).

\begin{tabular}{c|c}
\hline Ensaios realizados & Normas técnicas \\
\hline $\begin{array}{c}\text { Massa específica e massa específica } \\
\text { aparente }\end{array}$ & NBR NM 52 (2009)/NBR NM 53 (2009) \\
{$[9 ; 10]$} \\
\hline Massa unitária e volume de vazios & NBR NM 45 (2006) [11] \\
\hline Absorção de água & NBR NM 30 (2001)/NBR NM 53 (2009) \\
\hline Material pulverulento por lavagem & NBR NM 46 (2003) [13] \\
\hline Índice de forma & NBR 7809 (2006) [14]
\end{tabular}

\subsection{Cimento Portland}

O cimento utilizado neste estudo foi o CP II Z 32, escolhido a partir da seleção de materiais disponíveis nos laboratórios do Lactec. Este aglomerante foi caracterizado de acordo com os parâmetros estabelecidos da NBR 16697 (2018) [15] por técnica de fluorêscencia de raios-x (XRF), pastilha fundida em espectrofotômetro Panalytical, modelo Axios Max.

\subsection{Aditivo}

Tendo em vista que as fibras poderiam dificultar na trabalhabilidade dos concretos, provavelmente pela composição físico-química das fibras, foi necessário para as dosagens, o uso de um aditivo plastificante polifuncional redutor de água, linha Mira Set, a qual atendeu as específicações normatizadas pela NBR 11768 (2011) [16]. 
TANOBE, É. S. O. A.; MIRANDA, D. C.; BRONHOLO, J. L.; MARCONDES, C. G. N.; PORTELLA, K. F.; CARRERA, G.; BRAGANÇA, M. D. G. P. AVALIAÇÃO MECÂNICA DE CONCRETOS COM ADIÇÃO DE FIBRAS DE AÇAÍ E CURAUÁ. $4^{\circ}$ Simpósio Paranaense de Patologia das Construções (40 SPPC), artigo 4SPPC144, pp. 391 - 400, 2019. DOI: 10.4322/2526-7248.061

\subsection{Fibras Lignocelulósicas}

As fibras de açaí foram obtidas no instituto de pesquisa Lactec, situado em Curitiba PR, advindas inicialmente da cidade de Belém - PA. Essas foram separadas da semente e passaram por processo de moagem e peneiramento, configurando-as em comprimentos variados de até $5 \mathrm{~mm}$ e homogeneizados para aplicação nos concretos. Já as fibras de curauá, em condição in natura, foram adquiridas do laboratório de materiais de construção da PUCPR e arranjadas por corte em comprimento aproximado de $10 \mathrm{~mm}$. Na Figura 2 está ilustrado o estado das fibras obtidas:

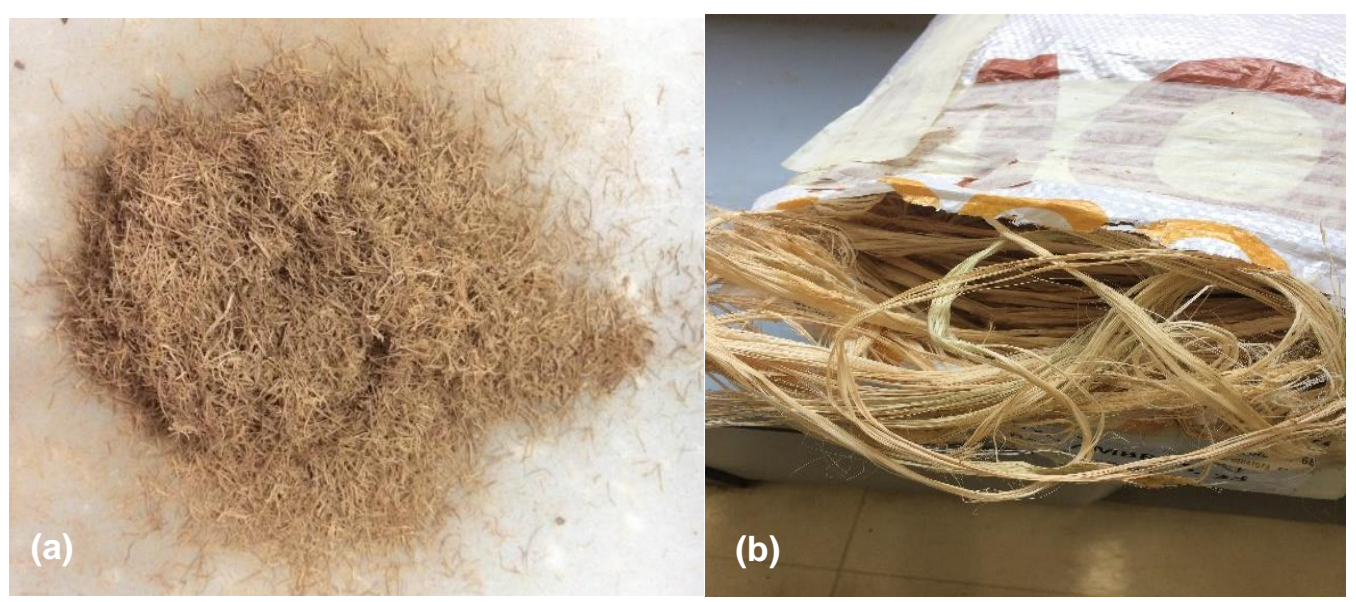

Figura 2: (a) fibras de açaí; (b): fibras de curauá.

\subsection{Dosagem dos concretos}

A composição do traço padrão do concreto adotado foi fundamentado no método sugerido pela equipe de FURNAS (1997) [17]. Este procedimento baseia-se previamente no consumo de aglomerante e no módulo de finura dos agregados. Logo, a composição do traço foi de: $1: 2,25: 2,97: 0,55$ (cimento : agregado miúdo : agregado graúdo : relação a/c), com um consumo de cimento de $257 \mathrm{~kg} / \mathrm{m}^{3}$. Cada traço avaliado encontra-se disposto na Tabela 2:

Tabela 2: Consumo de materiais utilizados para a produção de $1 \mathrm{~m}^{3}$ dos concretos avaliados.

\begin{tabular}{ccccccccc}
\hline \multirow{2}{*}{ TRAço } & \multicolumn{7}{c}{ MATERIAIS QUANTIDADES $\mathbf{( k g / \mathbf { m } ^ { 3 } )}$} & ABATIME \\
\cline { 2 - 8 } & Cimento & $\begin{array}{c}\text { Ag. } \\
\text { Miúdo }\end{array}$ & $\begin{array}{c}\text { Ag. } \\
\text { Graúdo }\end{array}$ & Água & $\begin{array}{c}\text { Fibra } \\
\text { de açaí }\end{array}$ & $\begin{array}{c}\text { Fibra de } \\
\text { curauá }\end{array}$ & Aditivo & $\begin{array}{c}\text { NTO } \\
\text { (mm) }\end{array}$ \\
\hline $\begin{array}{c}\text { Referência } \\
\text { (REF) }\end{array}$ & 257 & 578,25 & 763,29 & 141,35 & - & - & 0,8738 & 165 \\
\hline $\begin{array}{c}\text { Concreto } \\
\text { com 0,8\% de } \\
\text { fibra de açaí } \\
\text { in natura }\end{array}$ & 257 & 578,25 & 763,29 & 141,35 & 8,88 & - & 0,8738 & 35 \\
\hline $\begin{array}{c}\text { Concreto } \\
\text { com 0,8\% de } \\
\text { fibra de } \\
\text { curauá in } \\
\text { natura }\end{array}$ & 257 & 578,25 & 763,29 & 141,35 & - & 8,64 & 1,9018 & 0 \\
\hline
\end{tabular}


TANOBE, É. S. O. A.; MIRANDA, D. C.; BRONHOLO, J. L.; MARCONDES, C. G. N.; PORTELLA, K. F.; CARRERA, G.; BRAGANÇA, M. D. G. P. AVALIAÇÃO MECÂNICA DE CONCRETOS COM ADIÇÃO DE FIBRAS DE AÇAÍ E CURAUÁ. $4^{\circ}$ Simpósio Paranaense de Patologia das Construções (40 SPPC), artigo 4SPPC144, pp. 391 - 400, 2019. DOI: 10.4322/2526-7248.061

\subsection{Moldagem, cura e ciclagem dos corpos de prova}

As moldagens dos concretos foram realizadas em fôrmas cilíndricas de $(100 \times 200)$ $\mathrm{mm}$ e placas quadradas com dimensões de $(200 \times 200) \mathrm{mm}$ e espessura de $2 \mathrm{~cm}$, conforme as recomendações da NBR 5738 (2015) [18] e NBR 15845-8 (2015) [19] respectivamente. Após as dosagens, os corpos de prova foram mantidos em laboratório por um período de $24 \mathrm{~h}$. A cura foi realizada em câmara úmida com temperatura controlada de $(22 \pm 2){ }^{\circ} \mathrm{C}$ e umidade relativa do ar de $95 \%$ até as idades de 7 e 28 dias, conforme previamente estabelecidos para cada ensaio.

\subsection{Caracterização dos concretos}

Os concretos foram avaliados quanto ao seu desempenho físico e mecânico em seu estado endurecido, seguindo as normatizações recomendadas para cada ensaio, conforme listadas na Tabela 3.

Os ensaios de resistência à compressão e tração por compressão diametral foram realizados em prensa da marca EMIC com capacidade de carga de $200 \mathrm{tf}$, sendo definidos 2 CPs para cada idade (7 e 28 dias) do primeiro procedimento, 2 CPs para o segundo, respectivamente. Para o ensaio de resistência ao impacto de corpo duro, foram designados 3 CPs, em dispositivo normatizado pela NBR 15845-8 (2015) [18].

Tabela 3: Normatização utilizada para caracterização dos concretos

\begin{tabular}{c|c}
\hline Ensaios realizados & Procedimentos normativos \\
\hline Resistência à compressão & NBR 5739 (2018) [20] \\
\hline $\begin{array}{c}\text { Resistência à tração por compressao } \\
\text { diametral }\end{array}$ & NBR 7222 (2011) [21] \\
\hline Resistência ao impacto de corpo duro & NBR 15845-8 (2015) [19] \\
\hline
\end{tabular}

\section{Resultados e discussões}

\subsection{Caracterização de materiais}

Os agregados miúdo e graúdo empregados neste estudo apresentaram as caracterizações físicas apresentadas na Tabela 4. O agregado graúdo possuiu módulo de finura de 7,02 e diâmetro máximo característico de $25 \mathrm{~mm}$. Já o agregado miúdo apresentou módulo de finura de 2,96 e diâmetro máximo característico das partículas de $4,8 \mathrm{~mm}$.

Tabela 4: Resultados obtidos pela caracterização dos agregados (Fonte: Oliveira, 2019).

\begin{tabular}{c|c|c}
\hline Propriedades & Agregado miúdo & Agregado graúdo \\
\hline Massa específica seca $\left(\mathrm{g} / \mathrm{cm}^{3}\right)$ & 2,58 & 2,63 \\
\hline Massa específica & 2,60 & 2,59 \\
\hline Massa unitária $\left(\mathrm{kg} / \mathrm{m}^{3}\right)$ & 1570 & 1420 \\
\hline Volume de vazios (\%) & 39,1 & 45,9 \\
\hline Material pulverulento (\%) & 7,4 & 0,4 \\
\hline Absorção de água (\%) & 0,3 & 0,6 \\
\hline Índice de forma & - & 2,8 \\
\hline
\end{tabular}


TANOBE, É. S. O. A.; MIRANDA, D. C.; BRONHOLO, J. L.; MARCONDES, C. G. N.; PORTELLA, K. F.; CARRERA, G.; BRAGANÇA, M. D. G. P. AVALIAÇÃO MECÂNICA DE CONCRETOS COM ADIÇÃO DE FIBRAS DE AÇAÍ E CURAUÁ. $4^{\circ}$ Simpósio Paranaense de Patologia das Construções (40 SPPC), artigo 4SPPC144, pp. 391 - 400, 2019. DOI: 10.4322/2526-7248.061

Em relação a caracterização do cimento Portland CP II - Z 32, os resultados obtidos encontraram-se entre os parâmetros especificados pela NBR 16697 (2018) [16] que classificam esse cimento como composto com pozolana, com as características apresentadas na Tabela 5:

Tabela 5: Resultados obtidos pela caracterização do cimento CP II - Z 32.

\begin{tabular}{|c|c|c|c|}
\hline Exigências físicas e mecânicas & \multicolumn{2}{|c|}{ Métodos de ensaio } & Limites ABNT NBR 16697 \\
\hline Finura \#75 $\mu \mathrm{m}(200 \mathrm{~mm})$ & 2,3 & $\%$ & Classe $32 \leq 12 \%$ \\
\hline Finura \#45 $\mu \mathrm{m}(325 \mathrm{~mm})$ & 9,6 & $\%$ & - \\
\hline Finura (método Blaine) & 3680 & $\mathrm{~cm}^{2} / \mathrm{g}$ & - \\
\hline Início de pega & 260 & $\min$ & $\geq 60 \min$ \\
\hline Fim de pega & 360 & $\min$ & $\leq 600$ min (exigência facultativa) \\
\hline Expansibilidade a quente & 0,0 & $\mathrm{~mm}$ & $\leq 5 \mathrm{~mm}$ \\
\hline Consistência normal & 27,6 & $\%$ & - \\
\hline Massa específica & 3,05 & $\mathrm{~g} / \mathrm{cm}^{3}$ & - \\
\hline $\begin{array}{c}\text { Resistência à compressão (3 } \\
\text { dias) }\end{array}$ & 22,9 & $\mathrm{MPa}$ & Classe $32 \geq 10 \mathrm{MPa}$ \\
\hline $\begin{array}{c}\text { Resistência à compressão (7 } \\
\text { dias) }\end{array}$ & 27,2 & $\mathrm{MPa}$ & Classe $32 \geq 20 \mathrm{MPa}$ \\
\hline
\end{tabular}

\subsection{Propriedades físicas e mecânicas dos concretos}

Os resultados dos ensaios de resistência à compressão ( 7 e 28 dias) estão apresentados na Figura 3. Já os valores obtidos dos ensaios de resistência à tração por compressão diametral (28 dias), em MPa, assim como os resultados do ensaio de resistência ao impacto de corpo duro (28 dias), em J, estão exibidos na Figura 4.
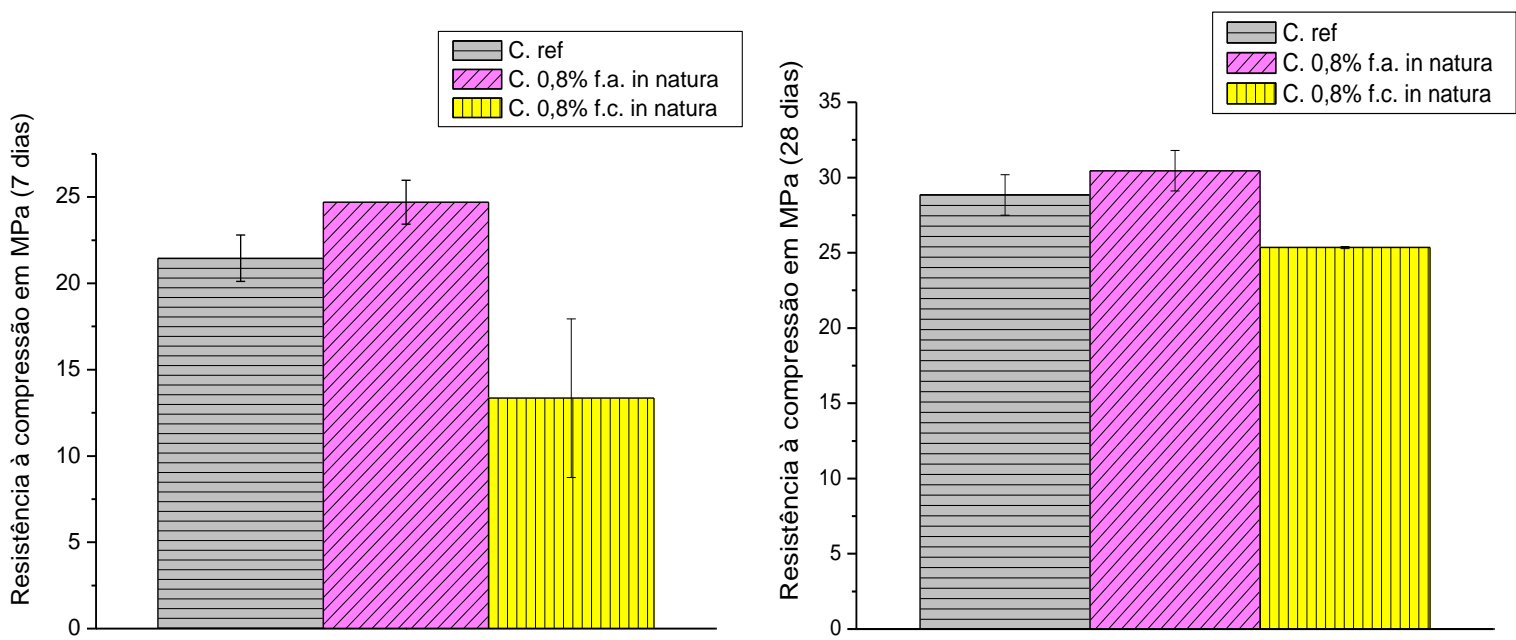

Figura 3: Resistência à compressão nas idades de 7 dias e 28 dias.

A partir dos resultados obtidos quanto a resistência à compressão na idade de 7 dias, foi possível observar que o traço que continham fibras de açaí (f.a.) apresentou valores, em MPa, sensivelmente maiores, em relação ao concreto de referência, com um aumento de $14,28 \%$. Em contrapartida, o traço com a adição das fibras de curauá (f.c.), apresentou um decréscimo de $37,76 \%$ na resistência à compressão do 
TANOBE, É. S. O. A.; MIRANDA, D. C.; BRONHOLO, J. L.; MARCONDES, C. G. N.; PORTELLA, K. F.; CARRERA, G.; BRAGANÇA, M. D. G. P. AVALIAÇÃO MECÂNICA DE CONCRETOS COM ADIÇÃO DE FIBRAS DE AÇAÍ E CURAUÁ. $4^{\circ}$ Simpósio Paranaense de Patologia das Construções (40 SPPC), artigo 4SPPC144, pp. 391 - 400, 2019. DOI: 10.4322/2526-7248.061

compósito, provocado indiretamente devido à falta de abatimento logo na etapa de dosagem, que infligiu sobre a trabalhabilidade e moldagem dos corpos de prova e consequentemente, sob o desempenho mecânico da amostra no ensaio. Pôde-se reforçar essa ideia, haja visto a discrepante variação do desvio padrão, pois, para o mesmo traço avaliado, encontraram-se valores de resistência à compressão na ordem de 17 e $10 \mathrm{MPa}$.

Um comportamento semelhante foi verificado nesses mesmos concretos para a idade de 28 dias. Os corpos de prova que continham as fibras de açaí mantiveram-se acima com valores de $5,54 \%$ superiores ao concreto de referência. Por sua vez, os concretos com as adições de fibras de curauá também apresentaram resultados semelhantes, com valores de resistência à compressão $12,13 \%$ abaixo do traço de referência. Logo, pode-se concluir que as fibras de açaí trouxeram benefícios aos concretos neste tipo de esforço solicitante, em contraste ao desempenho obtido pelas fibras de curauá.

Ainda assim, analisando apenas os concretos com $0,8 \%$ de fibra de curauá, verificouse um aumento de $89,9 \%$ da resistência mecânica à compressão entre as idades de 7 e 28 dias, sendo obtidos valores finais na ordem de 25,35 MPa. Com relação às diferenças encontradas nos desvios padrões para as idades de 7 e 28 dias, pode-se inferir que para a idade de 7 dias, a resistência mecânica à compressão foi mais afetada pela diminuição da trabalhabilidade em relação à idade de 28 dias. Infere-se, portanto, que tal material, embora não tenha diretamente contribuído com as características mecânicas, é passível de utilização em compósitos cimentícios, sendo necessários estudos adicionais a respeito de sua incorporação (com o uso de aditivos para a melhora da plasticidade, por exemplo).
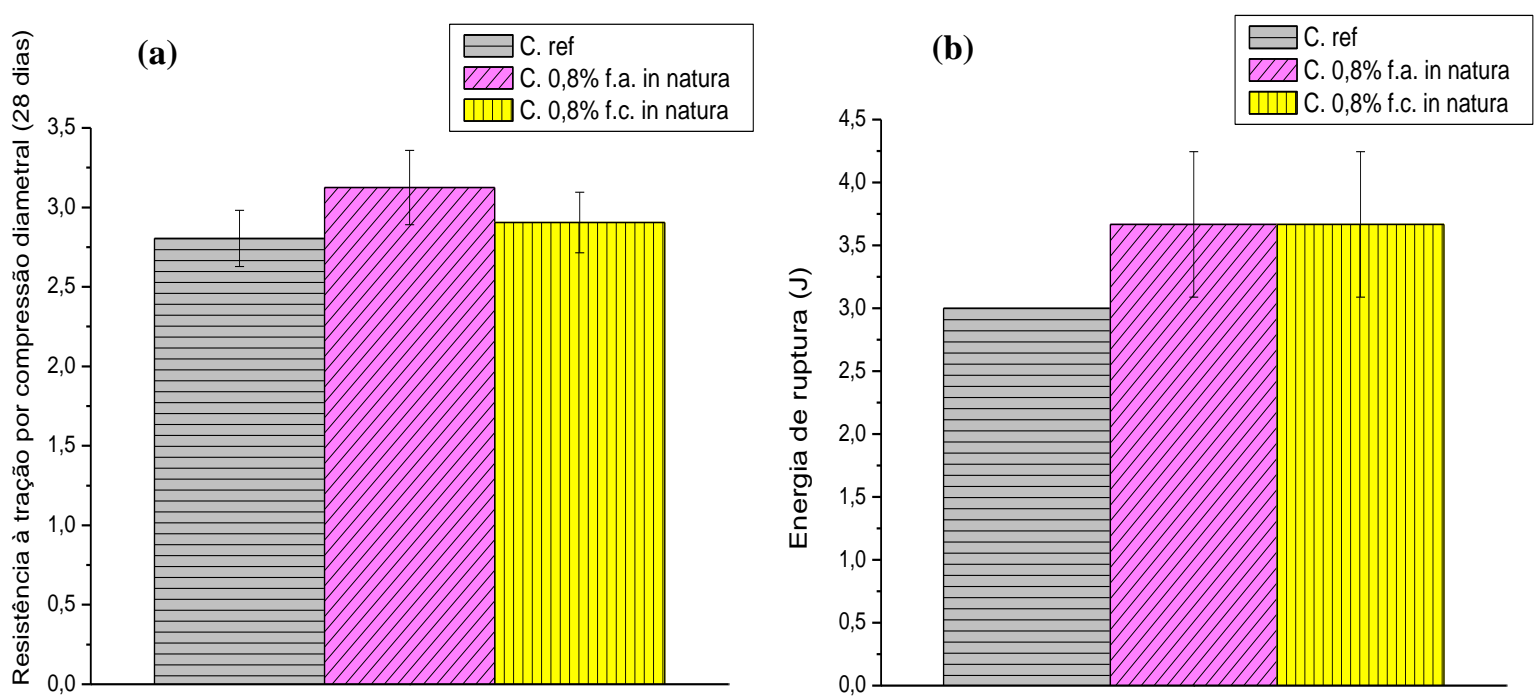

Figura 4: (a) Resistência à tração por compressão diametral (28 dias); (b): Resistência ao impacto de corpo duro (28 d).

Dos resultados obtidos do ensaio de resistência à tração, foi possível concluir que ambas as fibras in natura, permitiram um sensível aumento de 11,41\% e 3,56\% para as fibras de açaí (f.a.) e curauá (f.c.), respectivamente. Desta maneira, pode-se inferir que as fibras em estudo, quando solicitadas a um esforço de tração, tendem a 
TANOBE, É. S. O. A.; MIRANDA, D. C.; BRONHOLO, J. L.; MARCONDES, C. G. N.; PORTELLA, K. F.; CARRERA, G.; BRAGANÇA, M. D. G. P. AVALIAÇÃO MECÂNICA DE CONCRETOS COM ADIÇÃO DE FIBRAS DE AÇAÍ E CURAUÁ. $4^{\circ}$ Simpósio Paranaense de Patologia das Construções (40 SPPC), artigo 4SPPC144, pp. 391 - 400, 2019. DOI: 10.4322/2526-7248.061

dificultar levemente o rompimento do material, em relação aos concretos de referência, provavelmente pela sua aderência com a matriz cimentícia e a capacidade de absorver a energia aplicada. Esses resultados corroboraram com as informações de Siqueira (2005) [4] e Freire e Beraldo (2010) [5], no qual o emprego de fibras vegetais, de maneira geral, pouco afetou na resistência à tração nos concretos.

Ambos os traços contendo fibras in natura, quando comparados aos concretos de referência sob o desempenho no ensaio de resistência ao impacto de corpo duro, apresentaram um aumento de 33,3\% na energia de ruptura, em J. As amostras do traço do concreto referência apresentaram os mesmos resultados de energia de ruptura, logo não houve desvio em relação à média. Com isto, pode-se afirmar que as fibras conferiram maior tenacidade ao compósito formado, corroborando mais uma vez, com os estudos de Siqueira (2006) e Freire e Beraldo (2010), em que as fibras, por possuírem elevado número de vazios, permitem a absorção e a distribuição da energia recebida. Embora o comportamento frágil dos concretos se manteve, vale ressaltar que, na presença de fibras, após a fissuração, os materiais mantiveram-se agrupados de forma que não houve segregação das partes mais afetadas pela colisão do ensaio, conforme apresentadas na Figura 5.

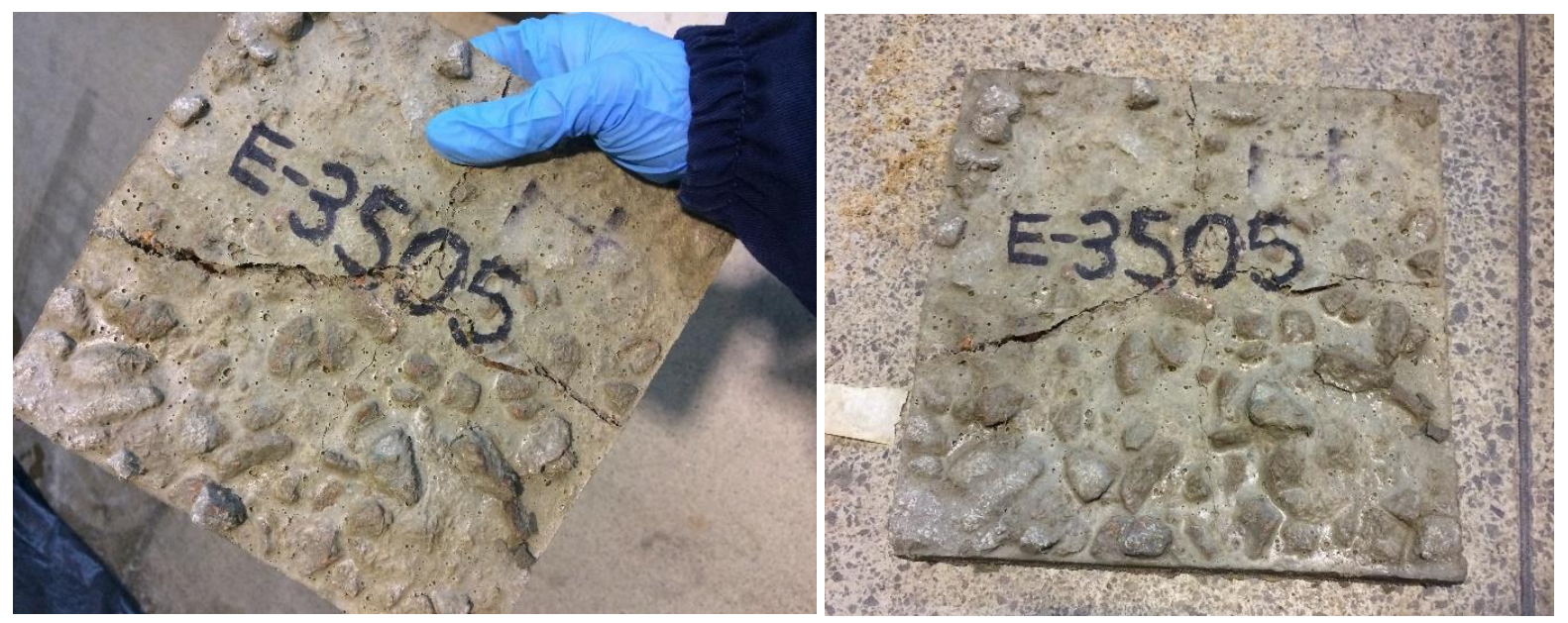

Figura 5: Estado da amostra após a fissuração causada por ensaio de resistência ao impacto de corpo duro (28 d).

\section{Conclusões}

Os resultados obtidos no presente estudo indicaram a possibilidade de utilização de fibras lignocelulósicas de açaí e curauá em compósitos cimentícios, in natura, sendo verificado um desempenho mecânico superior em termos de resistência à tração e de impacto de corpo duro.

Destacou-se, no entanto, o uso das fibras de açaí, que apresentaram desempenho superior de forma geral, com diferencial relativo à resistência mecânica à compressão axial, que apresentou-se até $5 \%$ superior àquela obtida para o concreto de referência. 
TANOBE, É. S. O. A.; MIRANDA, D. C.; BRONHOLO, J. L.; MARCONDES, C. G. N.; PORTELLA, K. F.; CARRERA, G.; BRAGANÇA, M. D. G. P. AVALIAÇÃO MECÂNICA DE CONCRETOS COM ADIÇÃO DE FIBRAS DE AÇAÍ E CURAUÁ. $4^{\circ}$ Simpósio Paranaense de Patologia das Construções (40 SPPC), artigo 4SPPC144, pp. 391 - 400, 2019. DOI: 10.4322/2526-7248.061

Estudos complementares em relação à utilização à longo prazo e à sua durabilidade fazem-se necessários, porém, reforça-se a viabilidade de uso, tanto do ponto de vista ambiental, com o aproveitamento diferenciado de um material residual local, quanto técnico. Nesse aspecto, evidenciou-se novamente, além do desempenho mecânico verificado, a propriedade de agregação após fissuração, dos concretos com adição de fibras, o que eleva a segurança na sua adoção, no caso de artefatos, como placas, vigas, pilares, postes e cruzetas.

\section{Agradecimentos}

Os autores agradecem à infraestrutura e ao apoio em recursos humanos e financiamento à CELPA/CEMAR projeto P\&D 00371-0023/2016, à Pontifícia Universidade Católica do Paraná, ao LACTEC, ao CNPq PIBITI, CNPq bolsa DT, processo 302672/2016-8; e aos demais envolvidos no desenvolvimento do estudo.

\section{Referências}

[1] Mehta, P. K.; Monteiro, P. J. (2005) Concreto: estrutura, propriedades e materiais. 2 ed. São Paulo: IBRACON, 674 p, 2014.

[2] BRAGANÇA, M. D. G. P. et al. Performance of concrete poles with organic and photocatalytic additions. Artigo: Espaço Energia, abril, 2014.

[3] IZQUIERDO, I. S.; RAMALHO, M. A. Aplicação das cinzas residuais e de fibra de sisal na produção de argamassas e concretos: revisão. Artículo de revision: Ingeniería ydesarrolo. Universidade de São Paulo, escola de engenharia de São Carlos, julho-dezembro, 2014.

[4] SIQUEIRA, J. E. L. Utilização de fibras naturais e sintéticas em argamassas de revestimento de alvenaria: estudo comparativo de desempenho. Dissertação (mestrado). Universidade Federal de Santa Catarina, agosto, 2006.

[5] FREIRE, W. J.; BERALDO, A. L. Tecnologias e materiais alternativos de construção. $1^{\circ}$ reimpressão. Editora Unicamp, Campinas, São Paulo, 2010.

[6] JÚNIOR, U. M. L. Fibras da semente do açaizeiro (Euterpe oleraceae Mart.): avaliação quanto ao uso como reforço de compósitos fibrocimentícios. Dissertação (mestrado). Porto Alegre, março, 2007.

[7] MESQUITA, A. L. Estudos de processos de extração e caracterização das fibras do fruto de açaí (Euterpe Oleraceae Mart.) da Amazônia para produção de ecopainel de partículas homogêneas de média densidade. Tese (doutorado) Programa de Pós-Graduação em Engenharia e Recursos Naturais da Amazônia, PRODERNA/ITEC da Universidade Federal do Pará, Belém, Pará, dezembro, 2013.

[8] OLIVEIRA, T. A. Autocicatrização autônoma de concretos com adição de nanorreservatórios de sílica e de $L D H s$ de nitrito sujeito à ação de íons cloreto ou sulfato. Dissertação (mestrado) em Engenharia Civil, no Programa de PósGraduação em Engenharia de Construção Civil - UFPR. Curitiba, 2019. 
TANOBE, É. S. O. A.; MIRANDA, D. C.; BRONHOLO, J. L.; MARCONDES, C. G. N.; PORTELLA, K. F.; CARRERA, G.; BRAGANÇA, M. D. G. P. AVALIAÇÃO MECÂNICA DE CONCRETOS COM ADIÇÃO DE FIBRAS DE AÇAÍ E CURAUÁ. $4^{\circ}$ Simpósio Paranaense de Patologia das Construções (40 SPPC), artigo 4SPPC144, pp. 391 - 400, 2019. DOI: 10.4322/2526-7248.061

[9] NBR NM 52 (2009) - Agregado miúdo - Determinação da massa específica e massa específica aparente. Associação Brasileira de Normas Técnicas - ABNT, Rio de Janeiro, Brasil.

[10] NBR NM 53 (2009) - Agregado graúdo - Determinação da massa específica, massa específica aparente e absorção de água. Associação Brasileira de Normas Técnicas - ABNT, Rio de Janeiro, Brasil.

[11] NBR NM 45 (2006) - Agregados - Determinação da massa unitária e do volume de vazios. Associação Brasileira de Normas Técnicas - ABNT, Rio de Janeiro, Brasil.

[12] NBR NM 30 (2001) - Agregados - Determinação da absorção de água. Associação Brasileira de Normas Técnicas - ABNT, Rio de Janeiro, Brasil.

[13] NBR NM 46 (2003) - Agregados - Determinação do material fino que passa através da peneira de $75 \mu \mathrm{m}$. Associação Brasileira de Normas Técnicas ABNT, Rio de Janeiro, Brasil.

[14] NBR 7809 (2006) - Agregado graúdo - Determinação índice de forma pelo método do paquímetro. Associação Brasileira de Normas Técnicas - ABNT, Rio de Janeiro, Brasil.

[15] NBR 16697 (2018) - Cimento Portland - Requisitos. Associação Brasileira de Normas Técnicas - ABNT, Rio de Janeiro, Brasil.

[16] NBR 11768 (2011) - Aditivos químicos para concreto de cimento Portland. Associação Brasileira de Normas Técnicas - ABNT, Rio de Janeiro, Brasil.

[17] FURNAS, E. Concretos: massa, estrutural, projetado e compactado com rolo Ensaios e propriedades. São Paulo: PINI, 695 p., 1997.

[18] NBR 5738 (2015) - Concreto - Procedimento para moldagem e cura de corposde-prova. Associação Brasileira de Normas Técnicas - ABNT, Rio de Janeiro, Brasil.

[19] NBR 15845-8 (2015) - Rochas para revestimento - Resistência ao impacto de corpo duro. Associação Brasileira de Normas Técnicas - ABNT, Rio de Janeiro, Brasil.

[20] NBR 5739 (2018) - Concreto - ensaio de compressão de corpos-de-prova cilíndricos. Associação Brasileira de Normas Técnicas - ABNT, Rio de Janeiro, Brasil.

[21] NBR 7222 (2011) - Concreto e argamassa - Determinação da resistência à tração por compressão diametral de corpos-de-prova cilíndricos. Associação Brasileira de Normas Técnicas - ABNT, Rio de Janeiro, Brasil. 